\title{
Ölüm Raporlarında Belirtilen Ölüm Nedenlerinin Kendi Aralarında ve ICD Kodlarıla Uyumunun Değerlendirilmesi
}

\author{
Consistency Assessment for the Causes of Death as Indicated in the Death \\ Certificates and in ICD Codes
}

\author{
Tanzer Korkmaz, Burçin Balaban \\ Abant Izzet Baysal Üniversitesi Tıp Fakültesi, Acil Tıp Anabilim Dalı, Bolu, Türkiye
}

Özet

\begin{abstract}
Amaç: Bu çalışma ile hastane otomasyon sisteminde yapılan kayıtlar ile ölüm belgelerindeki ölüm nedenleri arasındaki uyumun değerlendirilmesi planlanmıştır.

Yöntemler: Ölümü hastane içinde gerçekleşen olguların ölüm belgeleri ve hastane otomasyon sistem verileri geriye dönük olarak incelendi. Ölüm belgelerindeki ölüm nedenleri ve hastane kaynaklarındaki ICD kodları ile arasındaki uyum incelendi.

Bulgular: iki yıllık sürede toplam 351 olgunun 218'inin $(\% 62,1)$ erkek ve yaş ortalamalarının da $67,1 \pm 0,7$ olduğu tespit edildi. Hastane içi ölümlerin \%87,5'inin (n=307) 60 yaş ve üzerinde ve yoğun bakımda gerçekleştiği, ölüme kadar geçen süre ortalamasının $15,4 \pm 25,4$ saat olduğu görüldü. Doğrudan ölüme sebep olan hastalık veya durumların \%23,9'unun (n=84) kalp-pompa yetmezliği hastalıkları ve \%19,9'unun ( $n=70)$ da "kardiyopulmoner arrest" olarak kaydedildiği ve ilk kaydedilen ICD kodunda en fazla uyumluluğun $\mathrm{Ml}$ olgularında olduğu görüldü.
\end{abstract}

Sonuç: Hastane otomasyon sisteminde belirtilen hastalık kodları ile ölüm belgelerinde belirtilen ve hastanın ölümü ile sonuçlanan hastalık adları arasında farklılıklar gözlenmektedir. Ölüm istatistiklerindeki doğruluk ve tutarlık büyük oranda hekim verilerinin niteliğine bağlı olduğundan hasta kayıt ve ölüm nedenleri için gerekli ayrıntıların hekimler tarafından iyi bilinmesi gerekmektedir. (Haseki Tıp Bülteni 2014; 52: 103-10)

Anahtar Sözcükler: Hastane içi ölüm, ölüm nedeni, ölüm belgesi
Aim: In this study, we evaluated the consistency between the records made in the hospital automation system as well as the causes of death in the death certificates.

Methods: Death certificates for the cases occurred in the hospital and data of the hospital automation system were retrospectively analyzed.

Results: Out of 351 cases within a two-year period, 218 (62.1\%) were male and the mean age of the cases was $67.1 \pm 0.7$ years. Our findings showed that $87.5 \%(n=307)$ of the deaths in the hospital were among people 60 years of age and older and took place in the intensive care unit and the mean time to death was found to be $15.4 \pm 25.4$ hours. It was recorded that $23.9 \%(n=84)$ of diseases or conditions directly leading to death were heart failure and $19.9 \%$ $(n=70)$ of cases were cardiopulmonary arrest. The maximum consistency was found between the first recorded international classification of disease codes and myocardial infarction. Conclusion: Since the accuracy and consistency of death statistics are largely dependent on the nature of the physician-provided data, good knowledge of physicians regarding details on patient records and the causes of death is of great importance. (The Medical Bulletin of Haseki 2014; 52: 103-10)

Key Words: Mortality in-hospital, cause of death, death certificate
Yazışma Adresi/Address for Correspondence: Tanzer Korkmaz Abant İzzet Baysal Üniversitesi Tıp Fakültesi, Acil Tıp Anabilim Dalı, Bolu, Türkiye Tel.: +90 37425346 56/3160 E-posta: tanzerkorkmaz@gmail.com

Geliş Tarihi/Received: 11 Eylül 2013 Kabul Tarihi/Accepted: 8 Ekim 2013 


\section{Giriş}

Toplumun sağlık düzeyinin tespit edilmesi, önceliklerin belirlenmesi ve halk sağlığı politikalarının planlanması, uygulanacak kontrol ve müdahale programlarının düzenlenmesi istatistiki veriler ile ilişkilidir. Hastanelerde bu konuda önceliği olan verilerden bir tanesi de ölüm belgeleridir (1). Ölüm sebeplerinin doğru bir şekilde belirlenmesi sağlık alanında ölümlerdeki eğilimin tanımlanması, ölüme neden olan hastalıkların analizi ve bu konuda önlenebilir nedenlerin tespiti açısından önem arzetmektedir $(1,2)$. Bu istatistik sonuçları sağlık teşkilatı tarafından sık karşılaşılan hastalıkların saptanmasında ve önlenebilir nedenlerin belirlenmesinde kullanılmaktadır. Ancak ölüm istatistiklerinde güvenilirlik ve tutarlık büyük oranda formu dolduran kişilere ve onlar tarafından belirtilen verilerin niteliğine dayanmaktadır. Ölüm raporlarında belirtilen ölüm nedenlerinin çoğu zaman gerçek ölüm nedenlerini kapsamadığı sadece ülkemizde değil diğer ülkelerde de sorun olarak görülmektedir $(3,4)$. Bu sebeple ölüm belgelerinin universal, tek tip, özgün ve standardize edilmiş olması gerekmektedir (4). Ülkemizde bu sorunları en aza indirmek ve doğru veri elde edebilmek için Türkiye İstatistik Kurumu (TÜIK) tarafından hazırlanan ve Uluslararası Hastalık (ICD 10) sınıflamasına göre uluslarası standartlara uygun "Ölüm Nedeni İstatistikleri" projesi kapsamında yeni ölüm belgesi Ocak 2009'dan itibaren uygulamaya alınmıştır (5). Ilerleyen teknolojinin son yıllarda sağlık alanında daha fazla kullanılması ile hastanelerdeki hastalara ait tutulan dosya sistemi de terkedilmeye başlamıştır. Hastane otomasyon sistemleri (HOS) ile hastalara ait bilgi ve belgeler bilgisayar ortamında depolanmakta ve bu bilgilere ulaşım da kolaylaşmaktadır. Hastalara ait hastalık kodları da Avrupa Birliği uyum yasaları kapsamında ICD-10 (International Statistical Classification of Diseases and Related Health Problems) kodları ile standardize edilmiştir (6). Ancak HOS'ta belirtilen hastalık kodları ile ölüm belgelerinde belirtilen ve hastanın ölümü ile sonuçlanan hastalık adları arasında farklılıklar gözlenmektedir. Çalışmamızda 2009-2010 tarihleri arasında hastanemiz içerisinde meydana gelen ölümlerde düzenlenen ve TÜiK tarafından yeniden yapılandırılan ölüm belgelerinin incelenmesi, belirtilen ölüm nedenleri ile hastane otomasyon sisteminde belirtilen ICD 10 kodlamalarının uyumunun değerlendirilmesi amaçlanmıştır.

\section{Yöntemler}

Çalışma, Abant İzzet Baysal Üniversitesi Tıp Fakültesi Araştırma ve Uygulama Hastanesi'nde 2009-2010 tarihleri arasında tedavileri sürecinde ölen ve ölüm belgesi doldurulan hastaların verilerinden yararlanılarak retrospektif olarak yapıldı. Ölüm bildirimi formu savcılık tarafından doldurulan adli olgular çalışma dışında bırakıldı.
Olguların verileri ölüm belgelerinden ve HOS'den elde edildi.

Hastaların demografik özelliği, ikamet bölgesi, ilk başvuru kliniği ve ölümün gerçekleştiği servis kaydedildi. Olguların ölüm nedenleri; doğrudan ölüme sebep olan hastalık veya durum [Bölüm 1a], bu neden veya duruma yol açan diğer nedenler [Bölüm 1b, 1c, 1d] ve ölümün gerçekleşmesinde etkisi olan fakat ölüme neden olan hastalık veya durumla ilgisi olmayan diğer önemli durumlar [Bölüm 2] ve bu durumların başlangıcı ile ölüme kadar geçen süre kaydedildi (Şekil 1). HOS'unda kayıtlı olan tanı kodlarından (ICD-10) ilk üçü ve yazılan tüm ICD kodların adedi kaydedildi. illk üç ICD kodundan herhangi biri ile belirtilen hastalık, ölüm belgesindeki "asıl ölüm nedeni" bölümünde belirtilen durumu kapsiyor ise "uyumlu" kapsamıyor ise de "uyumsuz" olarak değerlendirildi (Tablo 1). ICD kodu ile ölüme neden olan hastalık arasındaki "uyum veya uyumsuzluk" tanımlamasında ölüm formunun doğru olarak doldurulmuş olması şartı aranmadı.

\section{ístatistiksel Analiz}

İstatistik analizi SPSS programı kullanılarak yapıldı. Demografik analizlerde ortalama ve standart sapma kullanıldı. Asıl ölüm nedeni ile ölümün gerçekleşme süresi arasındaki analizde One-way ANOVA ve posthoc Bonferroni testi kullanıldı. Hastalık kodları ve ölüm sebepleri arasındaki uyum karşılaştırmalarında $\chi^{2}$ testi kullanıldı. $P<0,05$ istatistiksel olarak anlamlı kabul edildi.

\section{Bulgular}

Hastanemizde 2009-2010 tarihleri arasında geçekleşen ve ölüm belgesi düzenlenen toplam 351 olgu tespit edildi. Olgu dağıımı 2009 yılında 179 (\%51) ve 2010 yllında 172 (\%49) olarak kaydedildi. Olguların yaş ortalamasının $67,1 \pm 0,7$ (yaş aralığı 1-93) olduğu ve 218 'ini $(\% 62,1)$ erkeklerin oluşturduğu tespit edildi. Hastane içi ölümlerin $\% 87,5^{\prime}$ inin ( $\left.n=307\right) 60$ yaş ve üzerinde gerçekleştiği, kadınlarda 70-80 yaş, erkeklerde ise 60-70 yaş aralığında sık görüldüğü tespit edildi (Şekil 2). Acil serviste gerçekleşen ölümlerin tamamının 40 yaş ve üzerinde [en sık 60-70 yaş aralığı $(n=11, \% 35,5)$ ] olduğu ve asıl nedenin de "kardiyopulmoner arrest" olarak belirtildiği tespit edildi. Olguların \%84 ( $n=295)$ oranında en sık Bolu'da yaşadığı, \%8,8'inin ( $n=31$ ) Düzce'de, \%3,2'sinin ( $n=11)$ Karadeniz bölgesinde, \%2'sinin ( $n=7)$ Marmara bölgesinde ve $\% 2$ 'sinin $(n=7)$ diğer bölgelerde yaşadığı tespit edildi. Olguların 63'ünün (\%17.9) ev hanımı, 36'sının (\%10.3) emekli, 28'inin (\%8.0) çiftçi, 18'inin iş̧̧i $(\% 5,1)$, 11 'inin $(\% 3,1)$ serbest meslek sahibi ve altısının memur olduğu $(\% 1,7)$ tespit edilirken $189^{\prime}$ unun $(\% 53,8)$ meslek kaydına ulaşılamadığı tespit edildi.

Ölüm bildirimlerinin ve ölüm belgelerinin düzenlenmesinin çoğunlukla asistanlar tarafından ( $n=305$, 
\%86,9) yapıldığı sadece \%13,1'inin öğretim elemanları tarafından yapıldığı tespit edildi. Olguların \%64,1'inin ( $n=225)$ ilk başvuru yerinin acil servis olmasına karşın sadece \%8, $8^{\prime}$ inin ( $\left.n=31\right)$ acil servis içinde öldüğü görüldü. Ölümün en sık yoğun bakımda gerçekleştiği tespit edildi (Şekil 3). Olguların ilk başvuru yerinin acil servis veya diğer poliklinikler olması ile ilk üç ICD kodunun uyumluluğu arasında anlamlı ilişki tespit edilmedi (1. ICD kodu için $p=0,47,2$. ICD kodu için $p=0,41,3$. ICD kodu için $p=0,66$ ).

Ölüm belgesinde ölüm nedeni bölümünde 'Bölüm 1' olarak belirtilen ve doğrudan ölüme sebep olan hastalık veya durumlar incelendiğinde; ölüm nedeninin \%23,9'unun ( $n=84$ ) kalp-pompa yetmezliği hastalıkları ve \%19,9'unun ( $n=70)$ da kardiyopulmoner arrest olarak belirtildiği tespit edildi. Doğrudan ölüme neden olan hastalık ve nedenler Şekil 4'de verilmiştir. Yaş dağılımına göre ölüm nedeni değerlendirildiğinde; olguların çoğunluğunu 60 yaş üstü hastaların oluşturduğu ve kalp-pompa yetmezliğinin en sık neden olarak belirtildiği tespit edildi (Tablo 2). Bölüm 2 ve Bölüm 3 olarak belirtilen hastalıkların dağılımı Tablo 3'de verilmiştir.

Ölüme neden olan hastalık ve durumun başlangııından ölüme kadar geçen süre ortalaması $15,4 \pm 25,4$ saat

\begin{tabular}{|c|c|c|}
\hline Bu bölūm sadece doktor t & Olüm Nedeni & \multirow[t]{2}{*}{$\begin{array}{c}\text { Hastaliğgn } \\
\text { başlangicindan } \\
\text { ölüme kadar } \\
\text { gecen yaklașik } \\
\text { süre }\end{array}$} \\
\hline \multicolumn{2}{|c|}{$\begin{array}{l}\text { Bōlūm I } \\
\text { Doğrudan ôlüme sebep a) }\end{array}$} & \\
\hline $\begin{array}{l}\text { olan hastalik veya } \\
\text { durum* } \\
\text { Onceki nedenler } \\
\text { b) }\end{array}$ & Bağhı olarak & \\
\hline $\begin{array}{l}\text { Ëger yukanda verilen } \\
\text { nedene yol açan ólüm c) }\end{array}$ & Bağht olarak & \\
\hline $\begin{array}{l}\text { ile sonuçlanan dunumlar } \\
\text { varsa, alta yatan durum } \\
\text { en son belirtilecek }\end{array}$ & Bağh olarak & \\
\hline $\begin{array}{l}\text { Bölüm II } \\
\text { OOlümün gerceklesmesine } \\
\text { etkisi olan, fakat olume } \\
\text { neden olan hastalik veya } \\
\text { durumla ilgili olmayan diger } \\
\text { Onemli durumlar yazalacaktur. }\end{array}$ & & \\
\hline $\begin{array}{l}\text { Bu bolûtme kalp arresti v } \\
\text { stalik, yaralanma veya kor }\end{array}$ & bi ôtû̀m sekilleri degil, ôtūme set & \\
\hline
\end{tabular}

Şekil 1. Ölüm nedenlerinin belirtildiği tıbbi ölüm belgesi

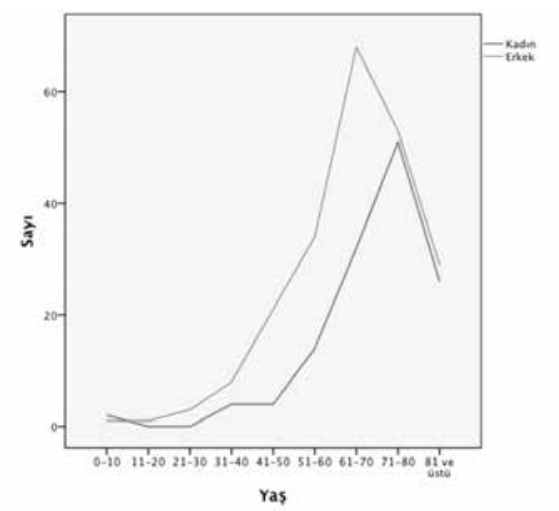

Şekil 2. Hastane içi ölümlerde yaş-cinsiyet dağılımı

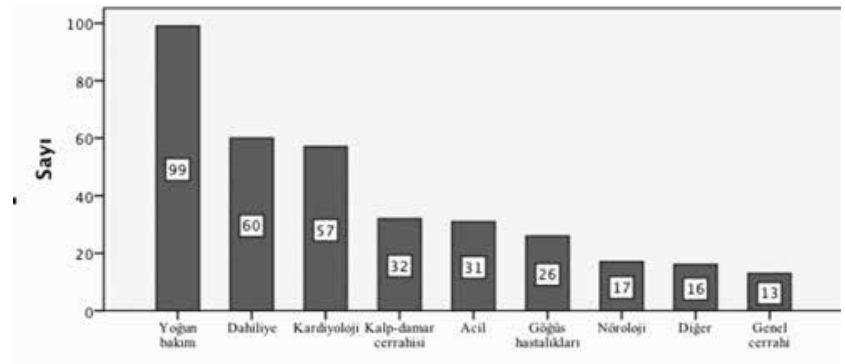

Şekil 3. Ölümlerin gerçekleştiği servislerin dağılımı

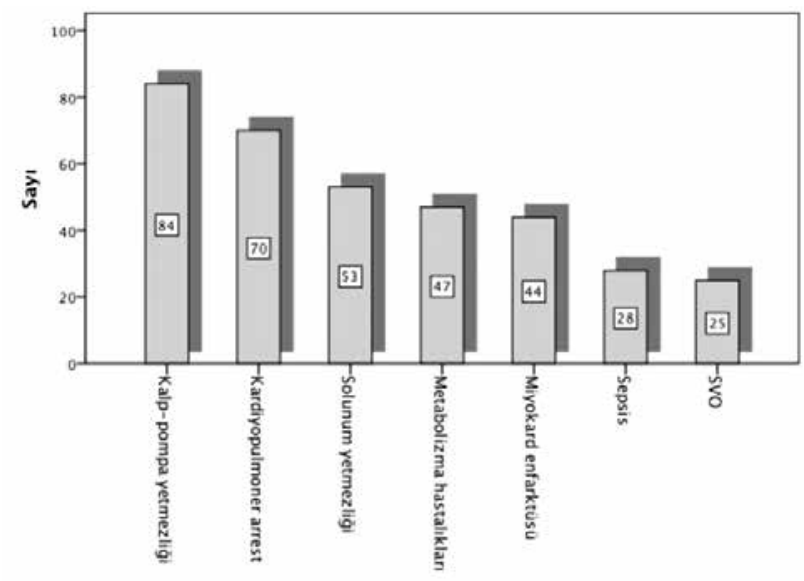

Şekil 4. Ölümin asıl nedeni (Bölüm 1) dağılımı

Kalp yetmezliği: Pulmoner ödem, kalp yetmezliği, hemo-pnomotoraks, hipotansiyon, hipovolemik şok

Kardiyopulmoner arrest: Kardiyak arrest, solunum arrest, kardiyopulmoner arrest, disritmi, ex duhul

Solunum yetmezliği: Asipirasyon, hemoptizi,pulmoner emboli, pnomoni Metabolizma hastalıkları: Akut böbrek yetmezliği, diyabet, hepatorenal hastalıklar, hepatik ensefalopati, multiorgan yetmezliği, metabolik asidoz Sepsis-DIC: Sistemik enfeksiyonlar, dissemine intravasküler koagulopati, septik şok

SVO: Serebro vasküler hastalık (iskemik-hemorajik)

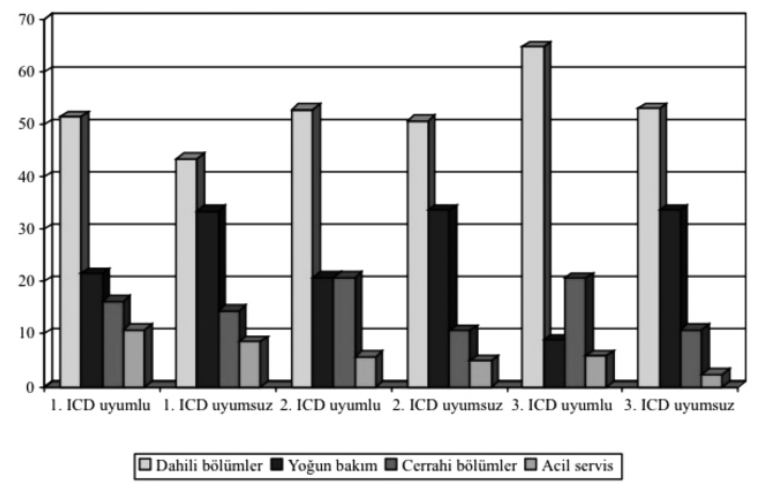

Şekil 5. Hastane otomasyon sistemine kaydedilen ICD kodları ile ölümün asıl nedeni arasındaki uyum dağılımı 
Tablo 1. Hastane otomasyon sisteminde kayıtlı olan ICD kodu ile ölüm belgesinde belirtilen ölüm sebebi arasındaki uyum ve/veya uyumsuzluğun örnekleri

\begin{tabular}{|c|c|c|c|}
\hline \multicolumn{2}{|c|}{$\begin{array}{l}\text { Örnekler } \\
{ }^{*} \mathrm{HOS}^{\prime} \text { deki }{ }^{\text {IICD kodları }}\end{array}$} & \multirow[t]{2}{*}{$\begin{array}{l}\text { Ölüm belgesindeki ölüm } \\
\text { nedeni }\end{array}$} & \multirow[t]{2}{*}{$\begin{array}{l}\text { Doğruluk } \\
\text { tipi }\end{array}$} \\
\hline Örnek A & & & \\
\hline 1. ICD kod: E87.2 & Asidoz & \multirow{3}{*}{ Kardiyopulmoner arrest } & Uyumsuz \\
\hline 2. ICD kod: R09.2 & Solunumsal arrest & & Uyumsuz \\
\hline 3. ICD kod: K76.8 & $\begin{array}{l}\text { Karaciğerin tanımlanmamış } \\
\text { hastalıkları }\end{array}$ & & Uyumsuz \\
\hline \multicolumn{4}{|l|}{ Örnek B } \\
\hline 1. ICD kod: 150.9 & Kalp yetmezliği, tanımlanmamış & \multirow{3}{*}{ Miyokardiyal enfarktüs } & Uyumsuz \\
\hline 2. ICD kod: E11.0 & İnsüline bağımlı olmayan diyabet & & Uyumsuz \\
\hline 3. ICD kod: I10 & Esansiyel Hipertansiyon & & Uyumsuz \\
\hline \multicolumn{4}{|l|}{ Örnek C } \\
\hline 1. ICD kod: J15.8 & Bakteriyal pnömoni, diğer & \multirow{3}{*}{ Pnömoni } & Uyumlu \\
\hline 2. ICD kod: $J 15.9$ & $\begin{array}{l}\text { Bakteriyal pnömoni, tanımlan- } \\
\text { mamış }\end{array}$ & & Uyumlu \\
\hline 3. kod: J18.1 & Lober pnömoni & & Uyumlu \\
\hline \multicolumn{4}{|l|}{ Örnek D } \\
\hline 1. ICD kod: N17 & Akut böbrek yetmezliği & \multirow{3}{*}{ Pnömoni } & Uyumsuz \\
\hline 2. ICD kod: D63 & Anemi, kronik tanımlı & & Uyumsuz \\
\hline 3. ICD kod: J15.9 & Bakteriyal pnömoni & & Uyumlu \\
\hline
\end{tabular}

\begin{tabular}{|c|c|c|c|c|}
\hline \multirow{2}{*}{$\begin{array}{l}\text { Doğrudan ölüme sebep olan } \\
\text { hastalık veya neden (Bölüm 1) }\end{array}$} & & \multicolumn{2}{|c|}{ Yaş aralığı } & \multirow{2}{*}{ Toplam } \\
\hline & & $0-60$ & 61 ve üstü & \\
\hline \multirow[t]{2}{*}{ Kalp-pompa yetmezlikleri } & $\mathrm{n}$ & 24 & 60 & 84 \\
\hline & $\%$ & 26,1 & 23,2 & 23,9 \\
\hline \multirow[t]{2}{*}{ Kardiyopulmoner arrest } & $\mathrm{n}$ & 16 & 54 & 70 \\
\hline & $\%$ & 17,4 & 20,8 & 19,9 \\
\hline \multirow[t]{2}{*}{ Solunum yetmezliği } & $\mathrm{n}$ & 18 & 35 & 53 \\
\hline & $\%$ & 19,6 & 13,5 & 15,1 \\
\hline \multirow[t]{2}{*}{ Metabolizma hastalıkları } & $\mathrm{n}$ & 11 & 36 & 47 \\
\hline & $\%$ & 12,0 & 13,9 & 13,4 \\
\hline \multirow[t]{2}{*}{ Miyokard enfarktüsü } & $\mathrm{n}$ & 10 & 34 & 44 \\
\hline & $\%$ & 10,9 & 13,1 & 12,5 \\
\hline \multirow[t]{2}{*}{ Sepsis-DIC } & $\mathrm{n}$ & 5 & 23 & 28 \\
\hline & $\%$ & 5,4 & 8,9 & 8,0 \\
\hline \multirow[t]{2}{*}{ SVO } & $\mathrm{n}$ & 8 & 17 & 25 \\
\hline & $\%$ & 8,7 & 6,6 & 7,1 \\
\hline \multirow[t]{2}{*}{ Toplam } & $\mathrm{n}$ & 92 & 259 & 351 \\
\hline & $\%$ & 100,0 & 100,0 & 100,0 \\
\hline
\end{tabular}


Tablo 3. Ölüm belgesinde Bölüm 2 ve Bölüm 3 olarak belirtilen hastalıkların dağılımı

\section{Bölüm 2 Hastalık ve durumlar}

\begin{tabular}{|l|l|}
\hline Myokard enfarktüsü & \\
\hline Sepsis & \\
\hline Cerrahi operasyon & \\
\hline Bypass-Aort operasyonları & \\
\hline Gastrointestinal durumlar & \\
Metabolizma hastalıkları & Akut böbrek yetmezliği \\
Kronik böbrek yetmezliği & \\
Hepatoensefalopati & \\
\cline { 2 - 2 } & \\
\cline { 2 - 2 } Siyabet & \\
\cline { 2 - 2 } & \\
\hline Akciğer kanserleri & \\
\hline Pulmone Emboli & \\
\hline Hipertansiyon & \\
\hline Diğer* & \\
\hline
\end{tabular}

Bölüm 3 Hastalık ve durumlar

\begin{tabular}{|l|l|}
\hline $\mathbf{n}$ & $\%$ \\
\hline 43 & 12,3 \\
\hline 37 & 10,5 \\
\hline 34 & 9,7 \\
\hline 33 & 9,4 \\
\hline 31 & 8,8 \\
\hline- & - \\
\hline 26 & 7,7 \\
\hline 20 & 5,7 \\
\hline 8 & 2,3 \\
\hline 5 & 1,4 \\
\hline 20 & 5,7 \\
\hline 20 & 5,7 \\
\hline 6 & 1,7 \\
\hline 8 & 2,3 \\
\hline 27 & 7,7 \\
\hline
\end{tabular}

\begin{tabular}{|l|l|l}
$\mathrm{KOAH} /$ Astım & 47 & 21,9 \\
\hline
\end{tabular}

Hipertansiyon

Kalp yetmezliği

Diyabet

Gastrointestinal maliniteleri

Barsak malinitesi

Karaciğer malinitesi

Solunum sistemi maliniteleri

Genitoüriner maliniteler

Serebrovasküler hastalık

Santral sinir sistemi maliniteleri

Hematolojik maliniteler

Diğer **

\begin{tabular}{|l|l|}
\hline $\mathbf{n}$ & $\%$ \\
\hline 77 & 21,9 \\
\hline 46 & 13,1 \\
\hline 45 & 12,8 \\
\hline 42 & 12,0 \\
\hline 40 & 11,4 \\
\hline- & - \\
\hline 24 & 6,8 \\
\hline 12 & 3,4 \\
\hline 17 & 4,8 \\
\hline 14 & 4,0 \\
\hline 11 & 3,1 \\
\hline 8 & 2,3 \\
\hline 8 & 2,3 \\
\hline 15 & 4,3 \\
\hline- & - \\
\hline
\end{tabular}

Bölüm 2: Doğrudan ölüme sebep olan nedene yol açan hastalık ve nedenler

Bölüm 3: Ölümün gerçekleşmesinde etkisi olan fakat ölüme neden olan hastalık veya durumla ilgili olmayan hastalık ve durumlar

Gastrointestinal durumlar: kanama, perforasyon, anemi

SVO: Serebro vasküler hastalık (iskemik-hemorajik)

KOAH: Kronik obstrüktif akciğer hastalı̆ı

*Diğer: Tüberküloz, batın içi apse, epilepsi,Vena-kava sendromu, plevral efüzyon, siroz, akciğer apsesi

**Diğer: Sarkoidoz, amiyolateral skleroz, epilepsi, obezite, ingüinal herni, hiperlipidemi, idiyopatik fibrosis, romatoid artrit, ailesel akdeniz ateşi, konjenital hastalıklar

Tablo 4. Illk üç ICD kodunun doğrudan ölüme neden olan hastalık veya nedenler ile uyumluluk dağılımları

\begin{tabular}{|l|l|l|lll|ll|l|}
\hline \multirow{2}{*}{$\begin{array}{l}\text { Doğrudan ölüme sebep } \\
\text { olan hastalık veya neden } \\
\text { (Bölüm 1) }\end{array}$} & & \multicolumn{5}{|c|}{ 1. ICD kodu } & \multicolumn{5}{c|}{ 2. ICD kodu } \\
\hline & & Uyumlu & Uyumsuz & Uyumlu & Uyumsuz & Uyumlu & Uyumsuz \\
\hline Kalp-pompa yetmezlikleri & $\mathrm{n}$ & 39 & 39 & 21 & 25 & 8 & 12 \\
\hline & $\%$ & 50 & 50 & 45,7 & 54,3 & 40 & 60 \\
\hline Kardiyopulmoner arrest & $\mathrm{n}$ & 11 & $\mathbf{5 5}$ & 2 & 31 & 2 & 20 \\
\hline & $\%$ & 16,7 & 83,3 & 6,1 & 93,9 & 9,1 & 90,9 \\
\hline Solunum yetmezlikleri & $\mathrm{n}$ & 19 & 31 & 11 & 22 & 9 & 13 \\
\hline & $\%$ & 38 & 62 & 33,3 & 66,7 & 40,9 & 59,1 \\
\hline Metabolizma hastalıkları & $\mathrm{n}$ & 10 & 33 & 5 & 27 & 6 & 16 \\
\hline & $\%$ & 23,3 & 76,7 & 15,6 & 84,4 & 27,3 & 72,7 \\
\hline MI & $\mathrm{n}$ & $\mathbf{3 2}$ & 11 & 5 & 14 & 5 & 6 \\
\hline & $\%$ & 74,4 & 25,6 & 26,3 & 73,7 & 45,5 & 54,5 \\
\hline Sepsis-DIC & $\mathrm{n}$ & 9 & 17 & 4 & 14 & 1 & 11 \\
\hline & $\%$ & 34,6 & 65,4 & 22,2 & 77,8 & 8,3 & 91,7 \\
\hline SVO & $\mathrm{n}$ & 10 & 14 & 5 & 7 & 3 & 5 \\
\hline & $\%$ & 41,7 & 58,3 & 41,7 & 58,3 & 37,5 & 62,5 \\
\hline Toplam & $\mathrm{n}$ & 130 & 200 & 53 & 140 & 34 & 83 \\
\hline
\end{tabular}


(zaman aralığı 0,5-120 saat) olarak tespit edildi. Ölümün gerçekleşme süreleri ile asıl ölüm nedenleri arasında yapılan analizde istatistiksel olarak anlamlılık tespit edildi $(p=0,012)$. Ileri analizde asıl ölüm sebebi kardiyopulmoner arrest olan hastaların (ortalama $7,4 \pm 16,3$ ) ölümünün sepsis-DIC olan hastalara göre (ortalama $25,3 \pm 25,4$ ) daha kısa sürede gerçekleştiği tespit edildi.

Her hasta için dosya sistemine kaydedilen ortalama ICD kod adedi 2,2 $\pm 1,4$ (aralık 1-9) olarak tespit edildi. ICD kod sayısı irdelendiğinde; en fazla tek ICD kodu yazıldığı $(n=133$, $\% 37,9)$, dört veya üzerinde ICD kodunun $(n=52, \% 14,8)$ da en fazla dahili bölümlerde kaydedildiği tespit edildi (iki ICD kodu $n=68, \% 19,4$ ve üç ICD kodu $n=77, \% 21,9)$. Beş ICD kodu yoğun bakım (4 olgu) ve dahili bölümlerde (6 olgu), altı ICD kodu cerrahi (1 olgu) ve dahili bölümlerde (3 olgu), yedi ve sekiz ICD kodu dahili bilimlerde (sırası ile 6 ve 1 olgu), dokuz ICD kodu ise sadece cerrahi bölümde (1 olgu) kaydedilmiştir.

ilk üç ICD kodunun doğrudan ölüme neden olan hastalık veya nedenlere göre uyumluluk oranları Tablo 4'de verilmiştir. Tablo incelendiğinde birinci olarak kaydedilen ICD kodlarından en fazla uyumluluğun MI olgularında en az uyumun da kardiyopulmoner arrest olgularında olduğu tespit edildi. MI olgularında üçüncü sırada kaydedilen ICD kod en fazla uyumlu olan kod olarak tespit edildi. Acil servisteki ICD kod uyumu değerlendirildiğinde (dahili branşlardan sonra); 1. ICD kod uyumunun diğer 2 ve daha fazla yazılan ICD kodlarına göre yüksek oranda olduğu tespit edildi (Şekil 5).

\section{Tartışma}

Ölümün nedenlerinin belirlenmesi, istatistiki datalarının sağlık politikalarında kullanılması, ölüm nedenleri ile kötü sağlık arasındaki farklılı̆ın incelenmesi, giderek artan yaşlı nüfusun spesifik ölüm nedenlerinin incelenmesi ve medikal literatür ile medikal tanılara katkı oluşturmaları açısından önem arzetmektedir $(2,4)$. Analizlerin doğru ve kullanılabilir olması açısından verilerin güvenilir ve problemi açıklayıcı nitelikte olması gerekmektedir. ABD'nin de ölüm istatistiklerinde, ası ölüm nedenleri ile kayıtlardaki bilgilerin uyumsuzluğu farkedildiğinden geniş katılımlı çalıştaylar yapılarak Avrupa Birliği ülkelerinde uygulanan ICD-10 sisteminin kullanılması üzerinde durulmuştur $(4,7)$. Ülkemizde de Avrupa Birliği uyum çalışmaları kapsamında "Ölüm Nedeni İstatistikleri" konusunda Sağlık Bakanlığı ile TÜik Başkanlığı'nın ortaklaşa yürüttükleri proje kapsamında Dünya Sağlık Örgütü ve Statistical office of the European Communities'in önerileri doğrultusunda "Ölüm Belgesi" geliştirilmiştir. Bu belge uyarınca ölümlere ait derlenen verilerden ülkemize ait ölüm nedeni istatistikleri üretilmesi amaçlanmıştır. Bu nedenle, yeni ölüm formu ve formun doldurulması sistematiğinin ilgili taraflara anlatılması gerekmektedir (2). Çalışmamızda ölümünün gerçekleştiği servisler incelendiğinde; literatür verileri ile uyumlu olarak yoğun bakım servisleri birinci sırada tespit edilmiştir $(3,8,9)$. Akar ve ark.'nın çalışmasında ölümün en sık sırası ile erişkin acilde ve yoğun bakımda gerçekleştiği $(\% 24,4, \% 8,6)$ tespit edilmiştir (10). Bir çok hastanede yatak sıkıntısı nedeniyle acil servisteki hastaların servislere hızlı nakil edilemediği bilinen durumlardandır. Bu nedenle hastaların stabilizasyonu sonrası ilgili servislere nakillerinin hızlıca yapılamadığı merkezlerde en sık ölümün acil servis içinde gerçekleştiğinin tespiti olağan görülmektedir. Hastaların servis nakillerinin hızlı yapılması, acil servis iş yükünü azaltacağı gibi spesifik tedavinin daha erken başlanmasında da yararlı olacaktır.

Ölüm verilerinde iki temel parametre bulunmaktadır. Birincisi, olguların demografik özellikleri ve ikincisi ise ölen kişinin ölüm nedenlerinin sıralanmasıdır. Okyay ve ark.'nın çalışmasında ölüm nedenlerinden ilk beş sıralamaya giren hastalık sınıflamasında erkeklerde akciğer $(\% 14,2)$, kadınlarda meme kanseri $(\% 8,3)$ tanımlanmaktadır (2). Ulusal Hastalık Yükü Çalışmasında, 15-59 yaş ölüm nedeninde birinci sırayı iskemik kalp hastalıkları $(\% 22,2)$, ikinci sırayı serebrovasküler hastalıklar $(\% 10,2)$, üçüncü sırayı ise trafik kazaları $(\% 5,2)$ almaktadır. Akar ve ark.'nın çalışmasında ölüm sebeplerinde ilk sırayı dolaşım sistemi $(\% 37,4)$ hastalıkları alırken ikinci sırayı kanserler $(\% 24,7)$ almaktadır (10). Bizim çalışmamızda ölüme doğrudan sebep olan hastalık ve durumlarda birinci sırada kalppompa yetmezliklerinin yer aldığı ve ölüm nedenleri içinde kanserlerin hiç yazılmadığı tespit edildi. Bu sonuç, hekimlerin ölüm belgesini doldururuken özensiz davranmalarından ziyade ölümü, kanserin komplikasyonuna bağlı gibi değerlendirmiş olduklarını düşündürmektedir. Mevcut durum ölüm formlarının doldurulması konusunda ilgili sağlık çalışanlarına verilecek eğitimin standart hale getirilmesini ve sürekliliğinin sağlanmasını gerekli kılmaktadır. Okyay ve ark.'nın yaptığı müdahale çalışmasında eğitim öncesinde ölüme neden olan asıl neden olarak $\% 40,1$ oranında "kardiyak arrest/kardiyopulmoner arrest" olarak tanımlanırken, eğitim verilmesinden sonra "kardiyak arrest/ kardiyopulmoner arrest" tanımlamasının hiç kullanılmadığı tespit edilmiştir (2). Ölüm raporlarına kardiyak arrest veya kardiyopulmoner arrest tanısının \%38,8 ile \%52,5 oranında yazıldığı benzer çalışmalar bulunmaktadır $(3,8,10-12)$. Bizim çalışmamızda da kardiyak nedenler birinci sırada belirtilirken "kardiyopulmoner arrest" tanımlaması \% 19,9 oranında kaydedilmiştir. Hastanemizde her ne kadar tüm sağlık personeline eğitim verilmemiş olsa da sağlık bakanlığınca yeni tanımlanan ölüm belgelerinin kullanıma girmesinden sonra ölüm belgelerinin idari personel tarafından gözden geçiriliyor olmasının "kardiyak 
arrest/kardiyopulmoner arrest" tanımlamasının \%19,9'da kalmasını açıklayabileceğini düşünmekteyiz.

Ölüm nedeni istatistikleri, endüstri çağında olan ülkenin ve toplumun gelişmişlik düzeyleri hakkında da bir bilgi kaynağını oluşturmaktadır. Endüstriyel ve teknolojik gelişmeler sonucunda yaşam süresinin arttığı bilinen bir gerçektir (4). Bu sebeple ölüm vakaları irdelendiğinde en sık yaşlı nüfusun tespiti anlaşılabilir bir durumdur. Literatür incelendiğinde ölümü gerçekleşen hastaların \%43,9$\% 56,7$ oranında 60 yaş ve üzeri hastalardan oluştuğu tespit edilmiştir (3,8-10). Bizim çalışmamızda yaşı hastalardaki ölüm oranı (60 yaş ve üzeri: $\% 87,5$ ) literartür verilerden daha fazla tespit edildi. Bir üniversite hastanesi olmamız nedeni ile daha çok son dönem hastaların refere edilmesinin bu oranda etkili olduğunu düşünmekteyiz. Altmış yaş ve üzeri grupta da en önemli ölüm nedenini iskemik kalp hastalıkları oluştururken $(\% 27,0)$ ikinci sırayı SVO $(\% 20,7)$ ve üçüncü sırayı da $\mathrm{KOAH}(\% 9,3)$ teşkil etmektedir (13). Hastanemizde gerçekleşen 60 yaş ve üzeri ölümlerde ilk sırayı kalp-pompa yemezliği $(\% 23,2)$, ikinci sırayı kardiyopulmoner arrest $(\% 20,8)$ ve üçüncü sırayı da solunum yetmezliği $(\% 13,5)$ oluşturmaktadır. Kardiyopulmoner arrest olarak tanımlanan ve özellikle yaşı ve kronik hastalıkların varlığında ölüm nedeninin tam olarak yakalanamadığı vurgulanmaktadır (11).

Bütün C ve ark.'nın yaptığı çalışmanın ölüm nedeni analizinde; ölüm belgesinde; 1 . sırada kardiyopulmoner arrest(\%52), ikincisırada santral sinir sistemi hastalıkları tespit edilirken hasta dosyalarında; 1 . sırada kardiyak hastalıklar (\%93), ikinci sırada ise santral sinir sistemi gelmektedir. Aynı çalışmada ölü duhul olarak alınan hastaların ölüm tutanağına bizim çalışmamızda olduğu gibi kardyopulmoner arrest yazıldığı tespit edilmiştir (3). Hekimlerin kardiyak nedenli olarak düşündükleri durumlarda da nedeni belli olmayan ölümlerde olduğu gibi "kardiyopulmoner arrest" yazma eğiliminde olmaları bu sonuçları açıklayabilir. Bütün bu sonuçlarda aile yakınları ile yapılan sözlü/görüşmeye dayalı otopsi (verbal otopsi) yönteminin kullanıııor olmasının da etkisi olduğunu düşünmekteyiz (14). Gürpınar ve ark.'nın çalışmasında da; ölüm belgelerinde 1. sırada "kardiyopulmoner arrest" $(\% 61,6)$ tespitine karşın hasta dosyalarında "kardiyopulmoner arrest" tanımlamasına rastlanmamıştır (15).

Sağlık politikalarının planlanması ve düzenlenmesinde etkisi büyük olan ölüm istatistiklerine kaynak oluşturan kayıtların doğru ve özenilerek doldurulması gereklidir. Ancak hasta dosyalarına yazılı olan ölüm nedeni ile ölüm belgesine yazılan ölüm nedeni arasında tutarsızlık farklı çalışmalarda da ifade edildiği gibi azımsanmayacak düzeydedir $(9,16,17)$. Shantibala K ve ark.'nın çalışmasında ölüm belgeleri ile ölüm nedenleri arasındaki majör hatalar $\% 38,3$ olarak tespit edilmiş ve sadece $\% 21,9$ oranında ölüm nedeninin mekanizmasının yazılı olduğu tespit edilmiş̧ir (17). Çilingiroğlu ve ark. çalışmasında hasta dosyası ile ölüm belgesindeki ölüm nedeni arasında \%36,7 oranında tutarsızlık tespit edilmiştir (9). Hastanemizde "hastane otomasyon sistemi" kullanılmaya başlandığı için acil servis dışındaki diğer bir çok poliklinikte yazılı hasta dosyası bulunmamaktadır. Bunun yerine dijital olarak otomasyon sistemine direkt kayıt yapılmakta ve hastalık tanı kodları işlenmektedir. Bu nedenle gelecekte hastalar hakkında bilgi edinilmesinin tek yolunun otomasyon sistemi olacağı öngörüldüğünden çalışmamızda; ICD kodları ile ölüm belgesindeki ölüm nedenleri karşılaştırıldı. Çalışmamızda ICD kodları ile ölüm belgelerindeki ölüm nedenleri arasında en fazla uyum MI vakalarında tespit edilmiştir. Hala ölüm nedeni olarak "kardiyopulmoner arrest" yazıldığı için en fazla uyumsuzluk da burada görülmektedir. Ölüm belgesindeki ölüm nedeni (MI olgularında) ile en fazla uyum üçüncü sırada yazılan ICD kodu ile tanımlanmışır. Birinci sırada yazılan ICD kodu dahili branşlardan sonra en fazla acil serviste doğru tespit edilmiştir. Hastanın ilk değerlendirme esnasında ilk ICD kodunun sırf sistemi aktifleştirmek, tetkik isteyebilmek için bariz olan bulgu üzerinden tespit edilmesi ilk ICD kodunun uyumsuzluk oranını ve üçüncü ICD kodunun ise uyumunu açıklayabilir. ICD kod sayısının servislerde giderek artması hasta masraflarının tahsil edilebilmesi gerekliliğinden kaynaklanabilir. Çünkü hasta masraflarının karşılandığı "Sosyal Sigortalar Kurumu" tetkik ve tedavi ödemelerini ancak ICD kod uyumunu esas alarak yapmaktadır. Bunun sonucunda da hastaya uygulanan tetkik ve tedaviler için tanı aralığı hekimler tarafından geniş tutulmaktadır. Bu durum, gerçek ölüm nedenlerinin belirlenmesi konusunun genel bir sorun olduğunu ve doğru ve kaliteli verilere ulaşım açııından maliyet hesabı ile kayıt sisteminin farklı sistemlerde dizayn edilmesini gerekli kılmaktadır. Bu konuda yapılmış çalışmalara ulaşılamadığından literatür ile tartışılamamıştır.

Ölüm istatistiklerindeki doğruluk ve tutarlık büyük oranda hekim verilerinin niteliğine bağlı olduğundan ölüm belgesindeki ölüm nedenleri sınıflandırması için gerekli ayrıntıların formu dolduran ve belgeyi onaylayan kişiler tarafından iyi bilinmesi gerekmektedir. Ölüm belgelerini dolduran ve HOS'unu kullanan sağlık çalışanlarının (özellikle araştırma görevlileri) süreç içinde sürekli değiştiği göz önünde bulundurularak eğitim programlarının sürekliliği planlanmalıdır.

\section{Kaynaklar}

1. Budakoglu II, Akgün HS. Sağlık Alanında Veri Toplama: Yakalama-Yeniden Yakalama Yöntemi. Kor Hek 2008;7:7580.

2. Okyay P, Bilgen MA, Dirlik M, Barut S. Change in Causes of Death Statistics Between Year 2008-2009 in the Practice and Research Hospital of Adnan Menderes University: An Intervention Study. ADÜ Tıp Fakültesi Dergisi 2011;12:10. 
3. Bütün C, Çelik M, Kılıççıoğlu B. The Evaluation of Death Causes in Death Certificates. C. Ü. Tıp Fakültesi Dergisi 2006;28:4.

4. Rosenberg HM. Cause of death as a contemporary problem. J Hist Med Allied Sci 1999;54:133-53.

5. Resmi istatistik programı 2007-2011 2011yilı izleme raporu. http://www.tuik.gov.tr/rip/doc/RIP2011_IzlemeRaporu. pdf2011. Türkiye İstatistik Kurumu: Ankara.

6. Ölüm Nedenlerinin Belgelenmesi. http://www.tuik.gov. tr/indir/sid/olum_nedeni.zip. Türkiye İstatistik Kurumu: Necatibey Cad. No: 11406100 Ankara.

7. Jougla E, Pavillon G, Rossollin F, De Smedt M, Bonte J. Improvement of the quality and comparability of causes-ofdeath statistics inside the European Community. EUROSTAT Task Force on "causes of death statistics". Rev Epidemiol Sante Publique 1998;46:447-56.

8. Vehid S, Köksal S, Aran SN, Kaypmaz A, Sipahioğlu F, Özbal AN. Cerrahpaşa Tıp Fakültesi'nde 1998 yilında meydana gelen ölümlerin dağılımının incelenmesi. Cerrahpaşa J Med 2000;31:1-56.

9. Cilingiroglu $N$, Subaşı $N$, Cicekli $O$, Kara $A V$, Ferlengez $E$, Kocatürk O. Hacettepe Üniversitesi Erişkin Hastanesi'ndeki 2004 Yılı Ölümlerinin Değerlendirilmesi. Hacettepe Sağlık Idaresi Dergisi 2005;8:307-24.

10. Akar T, Demircan A, Bildik F. Gazi Üniversitesi Tıp Fakültesi Hastanesi'nde bir yıl içerisinde meydana gelen ölümlerin değerlendirilmesi. Gazi Tıp Dergisi 2007;18:177-81.
11. Turla A, Kocakaya M. Defin ruhsatı (ölü gömme izin kağıdı) düzenlenmesindeki hata ve eksiklikler. Ondokuz Mayıs Üniversitesi Tıp Dergisi 2005;22:177-81.

12. Villar J, Perez-Mendez L. Evaluating an educational intervention to improve the accuracy of death certification among trainees from various specialties. BMC Health Serv Res 2007;7:183.

13. Hastalık Yükü Final Rapor, Ulusal Hastalık Yükü ve Maliyet Etkililik Projesi. T.C. Sağlık Bakanlığı Refik Saydam Hıfzıssıhha Merkezi Başkanlığı, Hıfzıssıhha Mektebi Müdürlüğü, RSHMB Hıfzıssıhha Mektebi Müdürlüğü, 2004, Aydoğdu Ofset Matbaacılık San. ve Tic. Ltd. Şti. İvedik Organize Sanayi, Ağaç İşleri Sanayi Sitesi 21. Cadde 598 Sokak No.20 http:// ekutuphane.tusak.gov.tr/kitaplar/turkiye_hastalik_yuku_ calismasi.pdf. Nisan 20132006: Ankara.

14. Gürpinar SS, Can G, Bölükbaşı O, Torun P. Analysis of mortality reports from a university hospital of Turkey. Forensic Sci Int 1997;88:169-71.

15. Eşiyok B, Cantürk G. Verbal otopsi ölüm nedenini belirlemede yaygın kullanım alanı bulabilir mi? Genel Tıp Dergisi 2005;15:133-36.

16. Myers KA, Farquhar DR. Improving the accuracy of death certification. CMAJ 1998;158:1317-23.

17. Shantibala K, Akoijam BS, Usharani L, Singh HN, Laishram $J$, Singh TA. Death certification in a teaching hospital-a one year review. Indian J Public Health 2009;53:31-3. 